\title{
Method for Diagnostics, Assessment, and Analysis of Investment Climate and Risks
}

\author{
Gennadii Alexandrov $^{1}$, Irina Vyakina ${ }^{1} \&$ Galina Skvortsova ${ }^{1}$ \\ ${ }^{1}$ Department of Economics and Production Management, Tver State Technical University, Tver, the Russian \\ Federation \\ Correspondence: Irina Vyakina, Department of Economics and Production Management, Tver State Technical \\ University, Tver, the Russian Federation. Tel: 7-910-646-2255. E-mail: ivyakina@yahoo.com
}

Received: October 9, 2016

doi:10.5539/ass.v13n2p

\author{
Accepted: December 22, 2016 \\ Online Published: January 19, 2017 \\ URL: http://dx.doi.org/10.5539/ass.v13n2p10
}

\begin{abstract}
The paper suggests the author's method of analyzing the investment climate and assessing unsystematic investment risk. The authors propose an original non-traditional approach to the solution of two interrelated problems: investment climate diagnostics and investment risk level evaluation. The technique can be applied by both an investor for making an investment decision and an issuer for analyzing reasons of the low investment object attractiveness. It makes it possible to identify the barrier and restrictive factors determining a high risks and to develop measures to reduce them. The advanced algorithm, step-by-step methodology, and decision support system for assessing investment climate and unsystematic investment risk were described and formalized in the paper. Scientific and practical significance lies in the fact that the complex analysis and evaluation method proposed allows management decisions to be argued. The author's technique will significantly reduce the role of the subjective factor caused by expert evaluation and uncertainty factors, improve the validity and reliability of the investment climate and risk assessments, and help to make an adequate decision about risk elimination.
\end{abstract}

Keywords: investments, capital assets investment, investment climate, investment risks, assessment of investment risks

\section{Introduction}

Changing economic and geopolitical conditions, aggravating competition among producers, increasing customers' requirements for the quality of products and service level, changing industrial and management technologies call for the adequate assessment of the investment environment in terms of investment risks. An investment market is becoming more dependent on the investors' motivation in the ongoing situation due to geopolitical risk increase.

This calls for significant improvement in attractiveness of investment climate implying a more supporting environment for investment at all hierarchy levels of the economy. Moreover, while attracting foreign investments, greater importance is attached to the investment climate at the regional and national levels along with the situation shaping itself in specific businesses and industries.

At the same time, in our estimation, the problem of shaping the attractive investment climate is primarily rooted in factors enabling or inhibiting the investments into the national economy, region, industry and particular enterprise.

In this relation it becomes urgent to promote factors inherent in the investment climate, facilitating or inhibiting the advancement of investment processes at all levels of economic hierarchy.

Despite considerable research efforts applied along these lines and with due respect to the significant contribution of participating academics and practitioners, it should be admitted that the issues of diagnostics and facilitation of attractive investment climate have not been sufficiently explored. This in its turn holds back the framing of validated and conclusive measures to reform the investment policy turning it towards supportive investment climate and finally towards advancing and intensifying investment processes.

\section{Method}

In this connection we consider that the existing and described methods are used in practice because either they 
are simple or academics have not yet suggested the methods to give practical benefits. There are many methods of assessing investment attractiveness and risks in the field of investment analysis but their practical advantages are not evident.

The different researchers have mainly focused on specific aspects of the investment climate assessment:

- industry aspect (Hrovatin, N., Dolšak, N., Zorić, J., 2016), (Lu, M., Cheung, C. M., Li, H., Hsu, S. C., 2016), (Colen, L., Persyn, D., Guariso, A., 2016), (Andrade, T., 2014);

- international aspect and globalization (Vithessonthi, C., 2016), (Fernandez, P., Aguirreamalloa, J., Acín, I. F., 2015);

- political and regulatory aspect (Korutaro, B. \& Biekpe, N., 2013), (Alesina, A., Ardagna, S., Nicoletti, G., Schiantarelli F., 2005), (Dawson, J.W., 2006), (La Porta, R. et al, 1999), (Messaouda, B. \& Tehenib Z. G., 2014);

- institutional and legal aspects (Beck, T., Demirguc-Kunt, A., Levine, R., 2003), (Djankov, S. et al, 2002), (Johnson, S., McMillian, J., Woodruff, C., 2002), (La Porta, R. et al, 1997);

- $\quad$ social and labor issues (Bertola, G. \& Rogerson, R., 1997), (Botero, J.C. et al, 2004).

Thus, the development of relevant method to identify and assess factors determining the investment climate, as well as the validation of means to enhance its attractiveness are vital for inducing the acceleration of investment processes.

The quantitative risk assessment methods used for choosing investment targets make it possible to logically and mathematically determine numerical measures of the proposed investment decision feasibility at both industrial and regional levels, with mathematical tools being used for developing and grounding the method of making an optimal investment decision in the conditions of high uncertainty and external environment impact.

To assess investment risks quantitatively statistics and probability methods are widely used. The methods can be based on a fuzzy-set model and probability economic calculations with the specific kind of activity in mind. They allow quantitative criteria to be determined for grounding investment decisions.

However, probability statistical methods require an infobase to correctly assess and forecast the whole set of risk investment economic elements.

When risks are assessed quantitatively, discount rates used at both regional and industrial levels can be calculated and adjusted. Besides, investment project risks are often assessed with analytical methods, risk factors being identified by experts.

Our analysis is governed by the idea that the best investment decision should not be guided by the simplicity of the methods described. It is necessary 'to take a more orderly approach in decision-making' and take into account versatile information which can lead to the best decision if only because [it] allows the decision-maker to consider a larger volume of relevant information.

In this connection we propose a methodology to systematize and synthesize investment attractiveness factors with an investment risk level taken into account. The approach is based on AVS-matrix method developed by the authors (AVS according to the all co-authors' names G. Alexandrov, I. Vyakina, G. Skvortsova). The method is described in the detailed article published by the authors in 2014 (Alexandrov G.A., Vyakina I.V., Skvortsova G.G., 2014). The method has been considerably improved and further applied to developing a new algorithm and information system (Certificate of State Registration of computer program in the Russian Federation No. 2015663672 "Software for assessing an investment climate and unsystematic investment risk". Issued on December 28, 2015).

The main idea of the matrix approach applied to AVS matrix is that factors determining investment attractiveness (rows) and their manifestation hierarchy levels (columns) identify an investment risk level (Figure 1).

The sixteen-block matrix is a formalized correlation of two measurement systems. The first one is a set of various factors conditioning an investment climate character and they are arranged in four groups (economic, administrative law, resource-technical, and socio-environmental). The second one reflects economic hierarchy levels where the indicated factors show up and are modified. It represents the interrelated elements of Business (B) - Industry (kind of economic activity) (I)- Region (R) - National economy (N).

where is a discount rate expressing risks and their sum by levels, formula (1), is a discount rate expressing risks and their sum by factors, formula (2) 


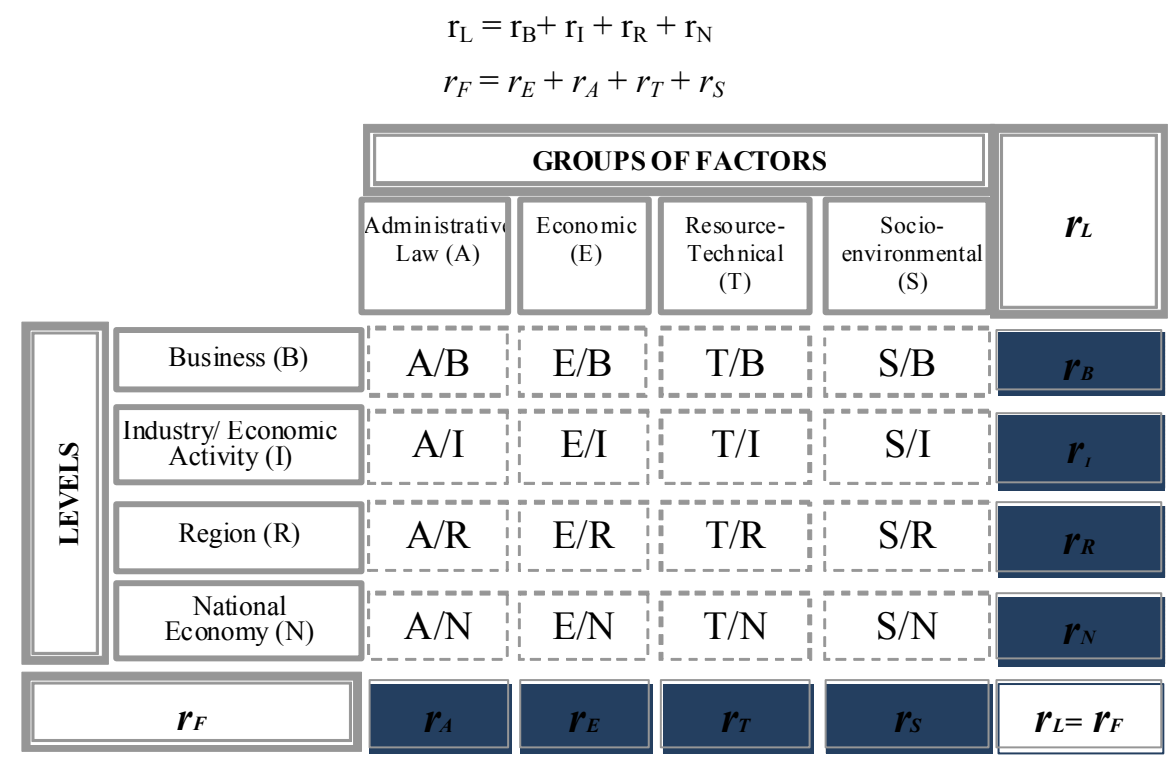

Figure 1. AVS matrix: the analysis of investment climate factors through investment risks

Thus, the discount rates expressing unsystematic risks at each level are considered and summed up both by economic levels (formula 1 ) and groups of factors (formula 2). The identity of both approaches is proved by $\boldsymbol{r}_{L}=$. $r_{F}$

An enterprise as a principal link of the system is a main investment object. Enterprise investment attractiveness in terms of economic factors is an investor's subjective perception of specific economic conditions stipulating their investment motivation. Through them [perception and motivation] an investor assesses the feasibility of the investment decision.

It should be understood that an investor, before they make an investment decision, appraises the economic circumstances in the industry, its value, the type of an economic strategy, its position in the region and national economy, etc. It should be mentioned that a large body of published material on the investment risk assessment at the industry level is available. The authors, as a rule, focus on the investment risk factors specific for industries and various economic activities.

Any investment object belongs not only to some industry but also to some territory, i.e. it is situated in some particular administrative region of the Russian Federation. Regional factors and regional affiliation of an investment object have a great influence on the investor's decision.

The investment space of the Russian Federation is known for its high heterogeneity, investments being concentrated in some particular regions with an investment climate attractive to investors. The problem of the regional risk assessment usually shows a correlation between the region production possibilities and investment risks, with peculiarities of a definite social and economic mesosystem being taken into account.

When foreign investments are attracted, the investment environment of the national economy and the image of its investment attractiveness to foreign investors play a pivotal role.

The next problem to pay attention to is the way of assessment of each matrix block component. In particular, the qualitative assessment of investment attractiveness factors can be based on statistical information and management experience data or done by experts.

As for the latter method it is based on the expert's subjective perception, professional experience, and individual approach to assessment. Such circumstances are clear to show subjectivity and not always adequate reflection of real risks. Therefore it is necessary to agree on measures minimizing the subjectivity influence before using the developed method.

Using the modified method based on AVS matrix we suggest a new algorithm providing for four successive steps instead of eight ones proposed earlier (Alexandrov, Vyakina, \& Skvortsova, 2014).

Appendix A-B show a flowchart of the new algorithm.

The method of assessment as a sequence of operations and definition of each step is described further. 


\section{STEP 1. Quantitative Assessment of Factors}

The first step makes an expert appraisal of investment climate factors by each group of factors (A, E., T, S) at different management levels. The experts assess the values of five factors of the specified group at each management level on a ten-score scale where 0 is the worst value and 10 is the best one.

Since it is necessary to clearly define the factors conditioning an investment climate nature presented in each matrix block, we determined and enunciated five major factors fully reflecting the situation in each group of factors under study at a specific level.

Thus, Step 1 carries out the following sequence of operations:

1.1 Let the quantity of factors in each group. Let the number of a group of factors be $i=4$ where (A, E, T, S). Let the number of a management level be $j=4$ where (B, I, R, N). Create a 3-D AVS matrix $A V S^{\prime}=\left(x_{i j z}\right)^{4,4,5}$ with 80 blocks of $4 \times 4 \times 5$ dimension where $x_{i j z}$ is an expert appraisal (score) of each factor within $0-1\left(x_{i j z} \in 0 \div 10\right)$, with the first index $i$ being the number of a group of factors, the second index $j$ being the number of a management level, the third index $z(1 \div 5)$ being the number of a factor in a group.

1.2 Expert appraisals (scores) of each factor are input by groups of factors and management levels. Consequently a 3-D AVS matrix $A V S^{\prime}=\left(x_{i j z}\right)^{4,4,5}$ is created, its elements being assigned a quantitative value $\mathrm{x}_{i j z}$ within $0-10$ $\left(x_{i j z} \in 0 \div 10\right)$.

1.3 Composite expert scores $X_{i j}$, which are the elements of a 2-D AVS matrix $A V S=\left(X_{i j}\right)^{4,4}$, are calculated by formula .

$$
X_{i j}=\sum_{z=1}^{5} x_{i j z}
$$

1.4 A 2-D AVS matrix $A V S=\left(X_{i j}\right)^{4,4}$ is generated, with each element having the value $X_{i j}$, within $0-50\left(X_{i j} \in 0 \div 50\right)$.

1.5 The sum of scores is calculated by groups of factors where $\left(X_{i} \in 0 \div 200\right)$.

$$
X_{i}=\sum_{j=1}^{4} X_{i j}
$$

1.6 The sum of scores is calculated by levels where $\left(X_{j} \in 0 \div 200\right)$.

$$
X_{j}=\sum_{i=1}^{4} X_{i j}
$$

1.7 The composite score is calculated where $\left(X_{\Sigma} \in 0 \div 800\right)$.

$$
X_{\Sigma}=\sum_{i=1}^{4} X_{i}=\sum_{j=1}^{4} X_{j}
$$

Thus, experts assess each factor quantitatively as an element of a 3-D AVS matrix $A V S^{\prime}=\left(x_{i j z}\right)^{4,4,5}$ with $4 \times 4 \times 5$ dimension, where each element $x_{i j z}$ is within the limits from 0 to $10\left(x_{i j z} \in 0 \div 10\right)$ where 0 is a minimum value as an absolute barrier to investments and 10 is a maximum value as the most attractive investment conditions.

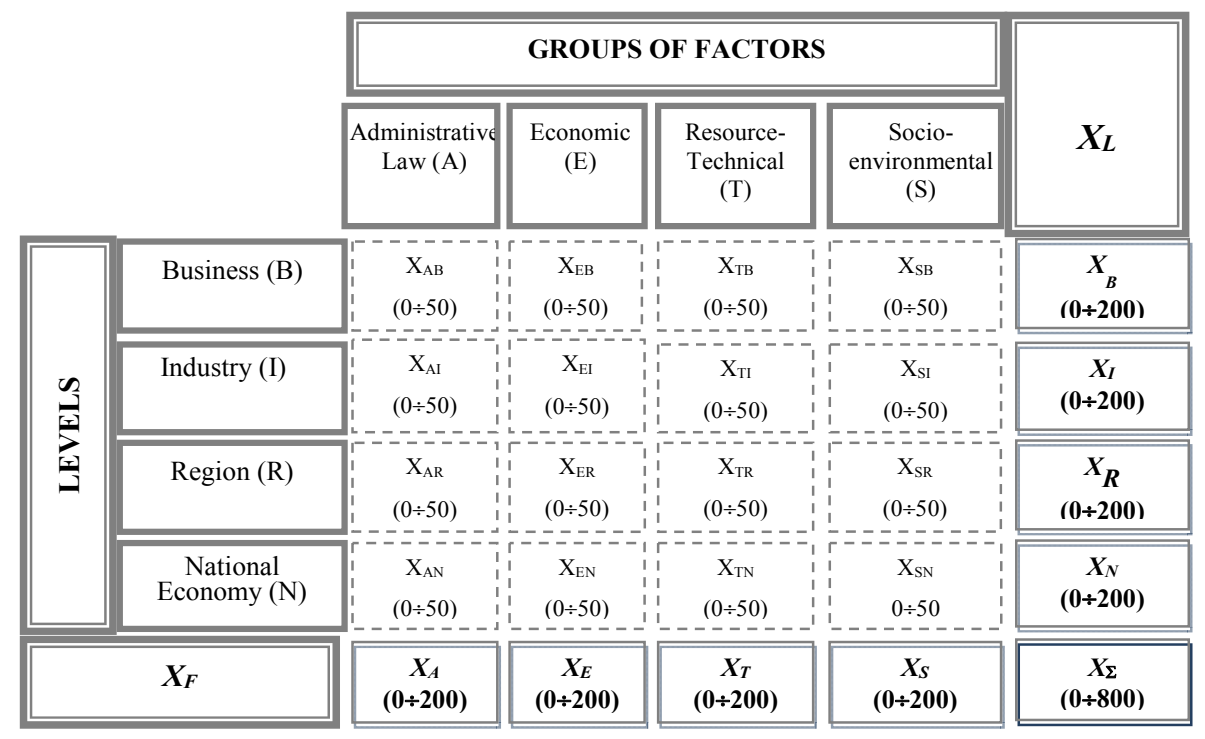

Figure 2. Intermediate AVS matrix for calculating an integral criterion of investment climate attractiveness $\left(X_{\Sigma}\right)$ 
It is important to emphasize that experts' functions are limited by Step 1which reduces the subjective impact on final assessments. All the other steps are done in investors' interests with elementary arithmetic operations.

The score of a specific group of factors at the appropriate level is summed up within $0-50\left(X_{i j} \in 0 \div 50\right)$. That is an assessment value of the impact of each group of factors at each level or $X_{i j}$ in a specific block of a 2-D AVS matrix $A V S=\left(X_{i j}\right)^{4,4}$.

Then we sum up all the scores by rows $\left(X_{j}\right)$, i.e. by management levels, and by columns $\left(X_{i}\right)$, i.e. by groups of factors, and calculate a composite score $X_{\Sigma}\left(X_{\Sigma} \in 0 \div 800\right)$.

Thus we derive an intermediate AVS matrix with 0 to 50 values in each block and the integral criterion of

investment climate being within $0-800$.

$$
X_{\Sigma}=X_{B}+X_{I}+X_{R}+X_{N}=X_{A}+X_{E}+X_{T}+X_{S}
$$

The intermediate matrix created is a base for calculating an integral criterion of investment climate and a discount rate determining an unsystematic risk premium. Figure 2 shows the form of the matrix.

\section{STEP 2. Specific Weight Calculation of Each Group of Factors $D_{i j}$}

The specific weight of each group of factors is calculated to analyze the degree of each group impact on the investment climate attractiveness. The analysis results show the vulnerabilities in an enterprise's investment attractiveness and help take measures to eliminate negative factor impact.

Step 2 includes the following operations:

2.1 The specific weight of each group of factors $D_{i j}=X_{i j} / X_{\Sigma}$ is calculated.

2.2 The sum is calculated by group of factors.

$$
D_{i}=\sum_{j=1}^{4} D_{i j}
$$

2.3 The sum is calculated by levels.

$$
D_{j}=\sum_{i=1}^{4} D_{i j}
$$

2.4 The output document in Figure 5 form is generated.

Figure 3 shows the calculation of the specific weight of investment climate factors.

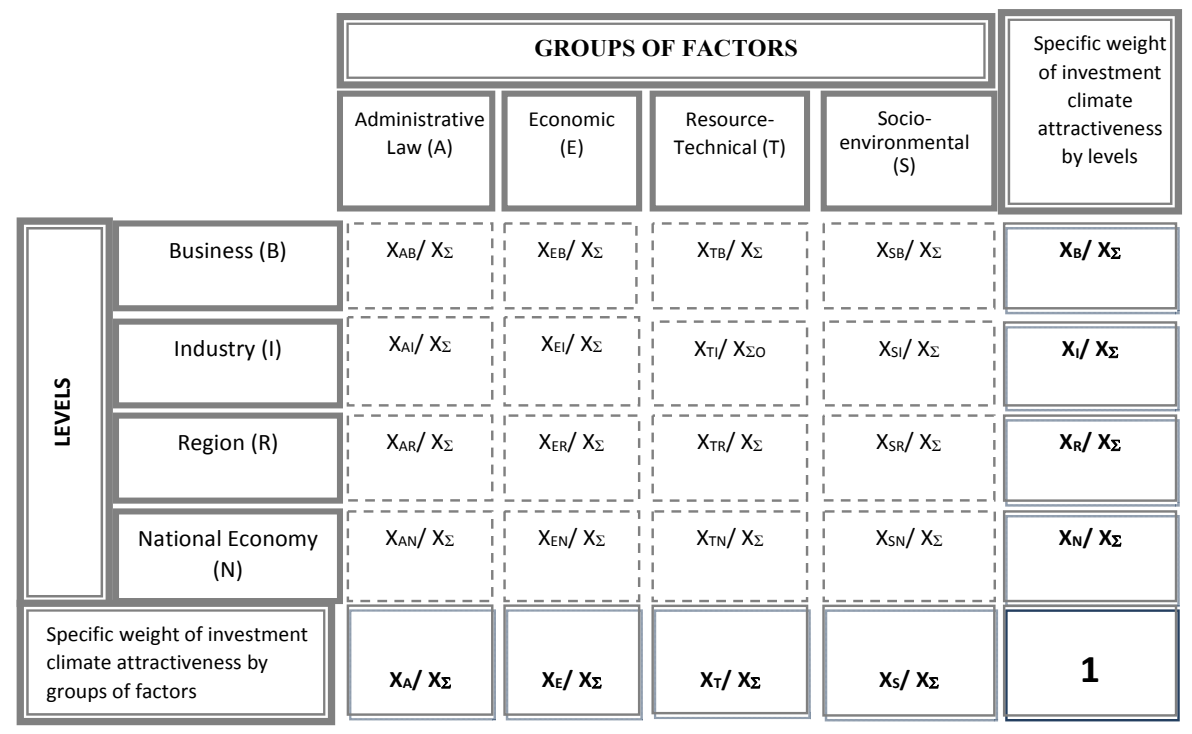

Figure 3. AVS matrix: the calculation of investment climate factor impact

\section{STEP 3. Calculation of an Integral Criterion of Investment Attractiveness $A_{i j}$ in $0 \div 1$ Appraisal Plan}

Step 3 recalculates the integral criterion of the analyzed object's investment attractiveness in AVS matrix (Fig. 2) 
with an $0 \div 1$ appraisal plan. The factors calculated in AVS matrix blocks are compared with a reference value of 800 chosen as a comparison base.

It means that all the initial investment scores given in 16 matrix blocks $X_{i j}(0-50$ scores $)$ are divided by the maximum integral criterion of the investment climate $X_{\Sigma}(800$ scores $)$ (Fig. 3).

Thereby we derive the scores of investment climate attractiveness from 0 to 1 (Fig.4). They are considered by both management levels and groups of factors within the limits of 0 to 0.25 . The integral criterion of the investment climate attractiveness $A_{\Sigma}$ is from 0 to 1 .

In this case the value corresponding to the most attractive investment climate for an investor and the least possible unsystematic risk is equal to 1 . The degree of $A_{\Sigma}$ criterion deviation from 1 shows the risk level at every management level:

- The closer $A_{\Sigma}$ is to 1 , the more attractive an investment climate is for the investor and hence the lower the risk level and unsystematic risk rate are.

- The closer $A_{\Sigma}$ is to 0 , the less attractive an investment climate is for the investor and hence the higher the risk level and unsystematic risk discount rate are.

Thus Step 3 carries out the following sequence of operations:

3.1 The integral estimate of investment climate attractiveness $A_{i j} i s$ calculated in coordinates from 0 to 1 ( $A_{i j} \in$ $0 \div 1)$.

$$
\begin{gathered}
A_{i j}=\frac{X_{i j}}{800} \\
A_{i}=\sum_{j=1}^{4} A_{i j}
\end{gathered}
$$

3.2 The sum is calculated by groups of factors.

3.3 The sum is calculated by levels.

3.4 The overall estimate is calculated within $0-1\left(A_{\Sigma} \in 0 \div 1\right)$

$$
\begin{gathered}
A_{j}=\sum_{\Sigma}^{4} A_{i j} \\
A_{\Sigma}=\sum_{i=1}^{4} \stackrel{4}{A_{i}}=\sum_{j=1}^{4} A_{j}
\end{gathered}
$$

3.5 The output document in Figure 4 form is generated.

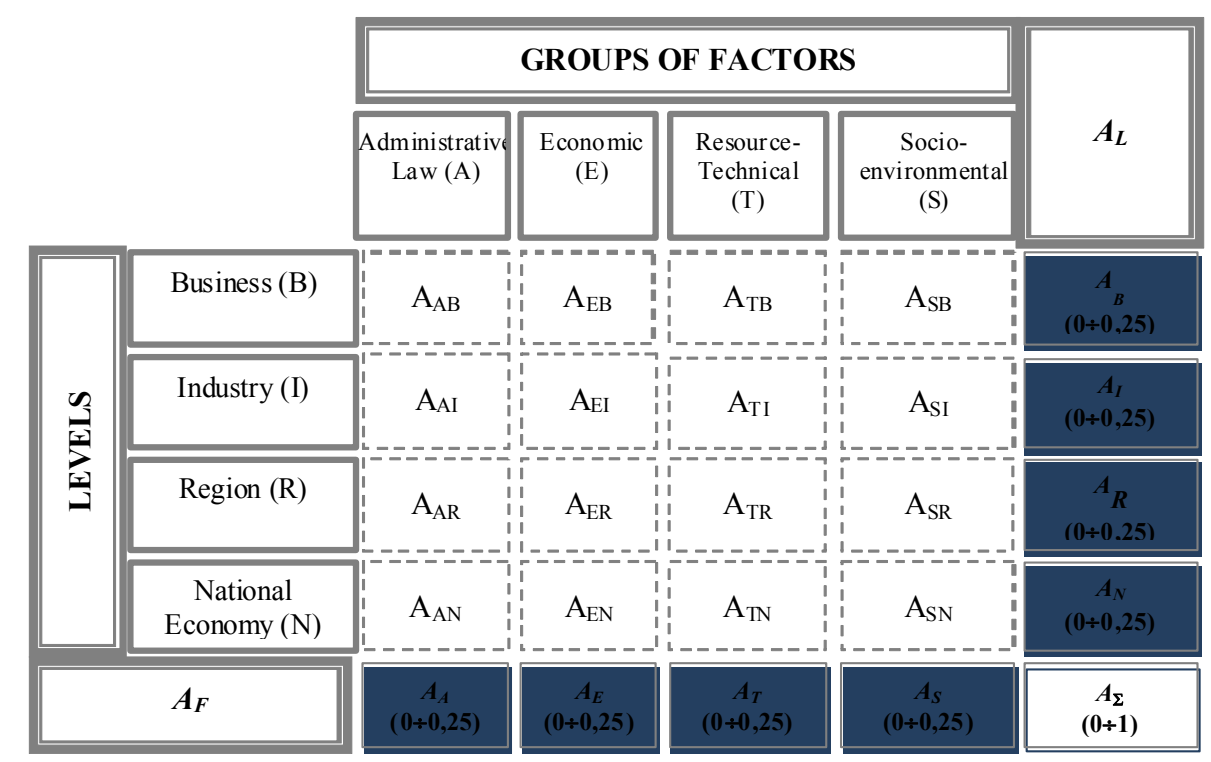

Figure 4. AVS matrix: the calculation of the integral investment climate criterion in an $0 \div 1$ appraisal plan 


\section{STEP 4. Calculation of Unsystematic Risk Premium $\mathbf{r}_{\Sigma}$}

Step 4 calculates discount rates expressing the premium for unsystematic risks for the investment object analyzed. The risk premium is calculated with an integral estimate of the investment climate attractiveness and risk-free discount interest rate.

In the context of the objective the elements of unsystematic risk are to be assessed. First it is necessary to specify a market value of the unsystematic discount rate $r_{f}$.

Then the matrix data of Figures 3 and 4 are used. We are to find the product of the risk-free discount rate $r_{f}$ and the ratio of each factor specific weight $D_{i j}=X_{i j} / X_{\Sigma}$. (Step 2) to the calculated integral criterion of the investment climate $\mathrm{A}_{\Sigma}$ (Step3)

$$
r_{j i}=\frac{X_{j i} / X_{\Sigma}}{A_{\Sigma}} \cdot r_{f}=\frac{D_{i j}}{A_{\Xi}} \cdot r_{f}
$$

where $D_{i j}$ is the corresponding matrix block shown in Figure 3, $\mathrm{A}_{\Sigma}$ is an integral criterion of investment climate attractiveness calculated with the matrix shown in Figure $4, r_{f}$ is a risk-free discount interest rate.

Thus, the risk premium can be calculated by groups of factors with eventual $\boldsymbol{r}_{F}$ being equal to $\boldsymbol{r}_{\boldsymbol{L}}$ in mind.

As a result the following sequence of operations is done at step 4:

4.1.A market value of risk-free rate $r_{f}$ is introduced.

4.2.The premium for unsystematic risk is calculated by formula $r_{i j}=\left(D_{i j} / A_{\Sigma}\right) \cdot r_{f}$.

4.3.The sum is calculated by groups of factors.

4.4.The sum is calculated by levels

$$
r_{i}=\sum_{j=1}^{4} r_{i j}
$$

$$
r_{j}=\sum_{i=1}^{4} r_{i j}
$$

4.5.The total premium for unsystematic risk is calculated with $r_{\Sigma}=r_{f}=r_{l}$.

$$
r_{\Sigma}=\sum_{i=1}^{4} r_{i}=\sum_{j=1}^{4} r_{j}
$$

4.6.The output document in Figure 5 form is generated.

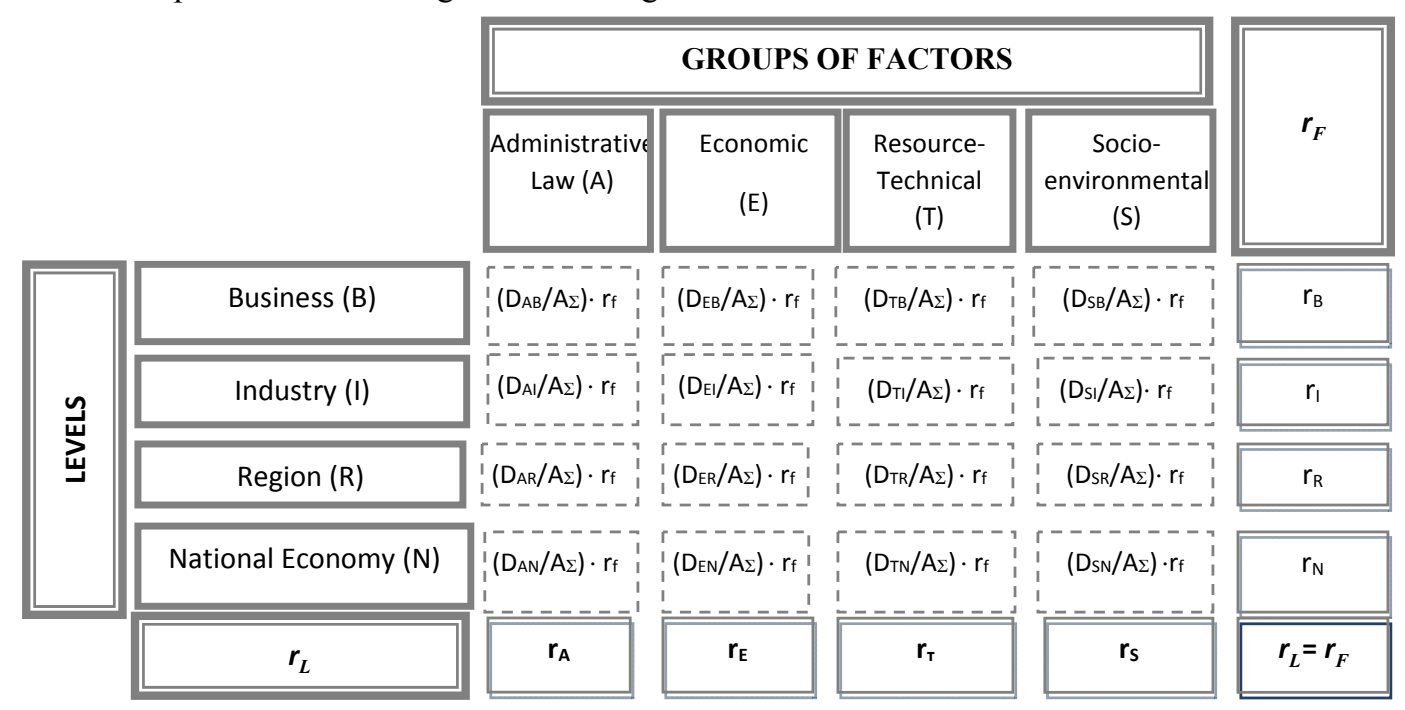

Figure 5. AVS matrix: calculation of a discount rate (risk premium) expressing unsystematic risks in investing

We use a risk-free discount rate as a base rate $\boldsymbol{r}_{\boldsymbol{f}}$ taking into account that the base rate is used in many methods to determine an unsystematic risk premium.

Since the experts' functions are limited by Step 1, all the other steps are done by the persons concerned about 
investors' interests and with elementary arithmetic operations.

\section{Results}

To computerize the investment climate diagnostics and attractiveness assessment we propose an information system based on AVS matrix.

The system (software) can be used by investors and lending institutions to assess an object's attractiveness and unsystematic risk premium, by researchers to analyze investment projects, by educational institutions and in any other cases where an expert appraisal of the investment climate is required at different levels.

The software functionality includes an investment climate assessment, each factor impact measurement and unsystematic risk premium calculation.

The software consists of four steps (form views) which can be switched with arrow keys located in the bottom left and right corners of the window. The views can be switched in both directions at any time of the program run. The results of the subsequent steps are recalculated in compliance with the values and scores corrected at the previous steps.

The first form view (Step 1) is used for filling in a three-dimensional matrix. Find tabs 'A' (Administrative law), 'Э' (Economic), ' $T$ ' (Resource-technical), 'C' (Socio-environmental) are used to switch between groups of factors.

Thus, the study allowed us to obtain the following results:

- examine methods for making investment decisions and determining investment risks on different economic levels, with industry characteristics taken into account

- describe a new approach to diagnosing an investment climate with the authors' AVS-matrix

- develop advanced algorithm and a step-by-step method for determining diversified investment risk (risk premium)

- describe a computer program as a decision support system for formalizing the subjective perception of objective quantitative risk assessments.

The proposed approach is assumed to elicit, first of all, the investment factors being barriers and constraints, work out adequate measures to increase the investment attractiveness of national economies, regions, industries, and enterprises, assess investment risks and reveal the factors conditioning assigned unsystematic risk and discouraging investments, considerably minimize subjectivity of expert appraisal and uncertainty factor, improve the validity and credibility of investment climate and risk assessments, and make an adequate investment decision.

\section{Acknowledgments}

The paper was supported by the Russian Federal Property Fund, the project «Formation of an adequate economic environment for innovative renewal of the fixed capital of enterprises as one of the conditions of Russia's security» № 16-02-00213.

\section{References}

Alesina, A., Ardagna, S., Nicoletti, G., \& Schiantarelli F. (2005). Regulation and investment. Journal of the European Economic Association, 3(4), 791-825. http://dx.doi.org/10.1162/1542476054430834

Andrade, T. (2014, 1 May). The impact of regulation, privatization and competition on gas infrastructure investments. Energy, 69, 82-85. http://dx.doi.org/10.1016/j.energy.2014.03.038

Alexandrov, G. A., Vyakina, I. V., \& Skvortsova, G. G. (2014). A method of investment climate analysis through calculation of diversifiable risk in the system of factors - levels - risks. Economic analysis: theory and practice, 37, 2-15. http://elibrary.ru/item.asp?id=22032120

Beck, T., Demirguc-Kunt, A., \& Levine, R. (2003). Law and finance: why does legal origin matter? Journal of Comparative Economics, 31(4), 653-675. http://dx.doi.org/10.1016/j.jce.2003.08.001

Bertola, G., \& Rogerson, R. (1997) Institutions and labor reallocation. European Economic Review, 41(6), $1147-1171$

Botero, J. C., La Porta, R., Lopez-de-Silanes, F., \& Shleifer, A. (2004). The regulation of labor. Quarterly Journal of Economic, 119(4), 1339-1382. http://dx.doi.org/10.1162/0033553042476215

Colen, L., Persyn, D., \& Guariso, A. (2016, July). Bilateral Investment Treaties and FDI: Does the Sector Matter? 
World Development, 83, 193-206. http://dx.doi.org/10.1016/j.worlddev.2016.01.020

Dawson, J. W. (2006). Regulation, investment and growth across countries. Cato Journal, 26(3), 489-509. http://object.cato.org/sites/cato.org/files/serials/files/cato-journal/2006/11/cj26n3-5.pdf

Djankov, S., LaPorta, R. Lopez-de-Silanes, F., \& Schleifer, A. (2002). The regulation of entry. Quarterly Journal of Economics, 117(1), 1-37. http://dx.doi.org/10.1162/003355302753399436

Fernandez, P., Aguirreamalloa, J., \& Acín, I. F. (2015, December). Required Market Risk Premium among countries in 2012. The Journal of Finance and Data Science, 1(1), 42-54. http://dx.doi.org/10.1016/j.jfds.2015.07.003

Hrovatin, N., Dolšak, N., \& Zorić, J. (2016, July 20). Factors impacting investments in energy efficiency and clean technologies: empirical evidence from Slovenian manufacturing firms. Journal of Cleaner Production, 127, 475-486. http://dx.doi.org/10.1016/j.jclepro.2016.04.039

Javorcik, B. S., \& Spatareanu, M. (2005). Do foreign investors care about labor market regulations? Review of World Economics, 141(3), 375-403. http://dx.doi.org/10.1596/1813-9450-3275

Johnson, S., McMillian, J., \& Woodruff, C. (2002). Property rights and finance. American Economic Review, 92(5), 1335-1356. http://dx.doi.org/10.1257/000282802762024539

Korutaro, B., \& Biekpe, N. (2013, January-March). Effect of business regulation on investment in emerging market economies. Review of Development Finance, 3(1), 41-50. http://dx.doi.org/10.1016/j.rdf.2013.01.001

La Porta, R., Lopez-de-Silanes F., Shleifer, A., \& Vishny, R. (1999). The quality of government. Journal of Law Economics and Organization, 15(1), 222-279. http://dx.doi.org/10.1093/jleo/15.1.222

La Porta, R., Lopez-de-Silanes, F., Shleifer, A., \& Vishny, R. (1997). Legal determinants of external finance. Journal of Finance, 52, 1131-1150. http://dx.doi.org/10.1111/j.1540-6261.1997.tb02727.x

Lu, M., Cheung, C. M., Li, H., \& Hsu, S. C. (2016, September). Understanding the relationship between safety investment and safety performance of construction projects through agent-based modeling. Accident Analysis \& Prevention, 94, 8-17. http://dx.doi.org/10.1016/j.aap.2016.05.014

Messaouda, B., \& Tehenib Z. G. (2014, December). Business regulations and economic growth: What can be $\begin{array}{llll}\text { explained? International Strategic } & \text { Management }\end{array}$ http://dx.doi.org/10.1016/j.ism.2014.03.001

Vithessonthi, C. (2016, September). Capital investment, internationalization, and firm performance: Evidence from Southeast Asian countries. Research in International Business and Finance, 38, 393-403. http://dx.doi.org/10.1016/j.ribaf.2016.04.019 


\section{Appendix A}

The algorithm of determining an unsystematic risk premium with AVS-matrix (beginning)

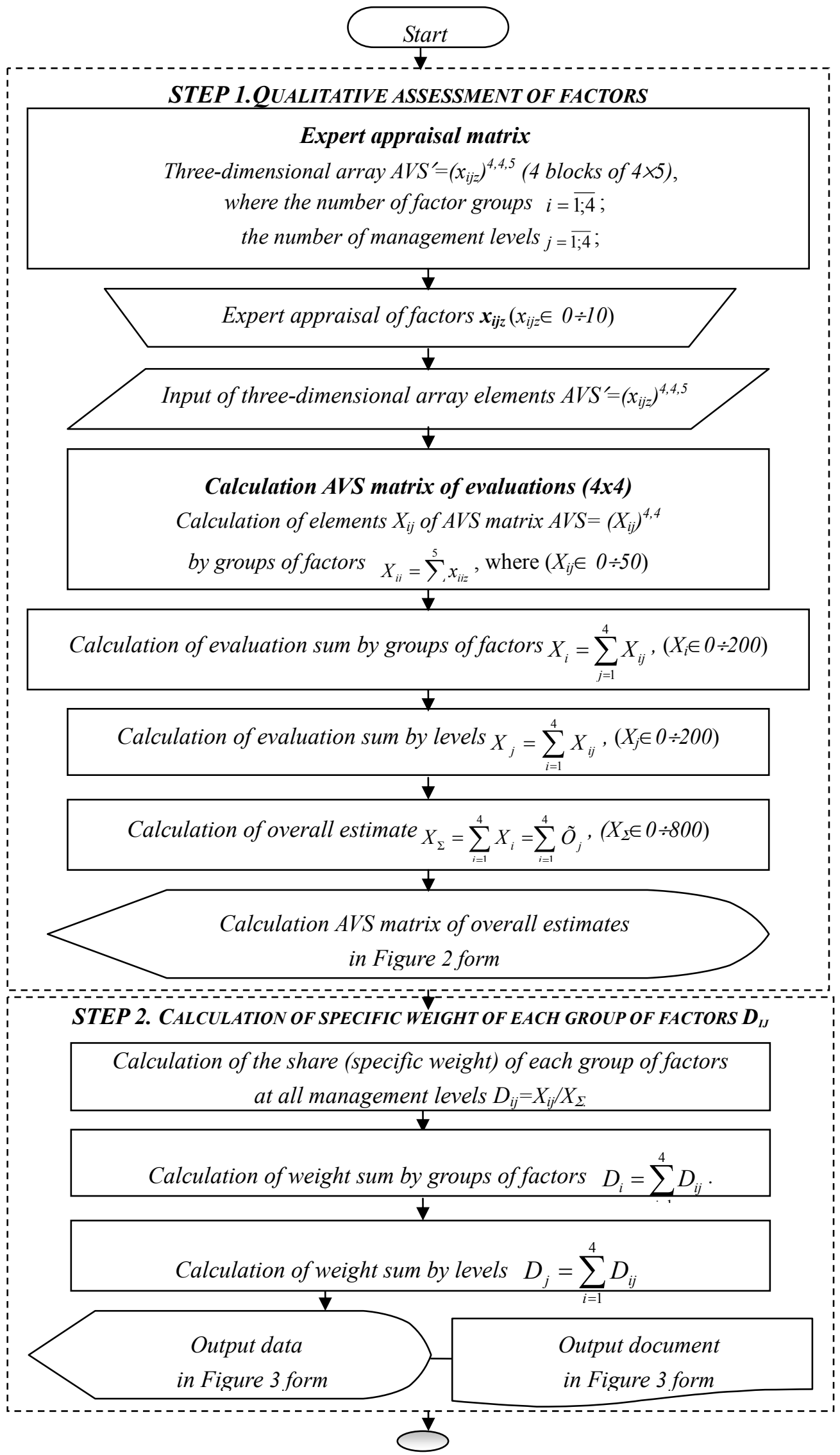




\section{Appendix B}

The algorithm of determining an unsystematic risk premium with AVS-matrix (continuation)

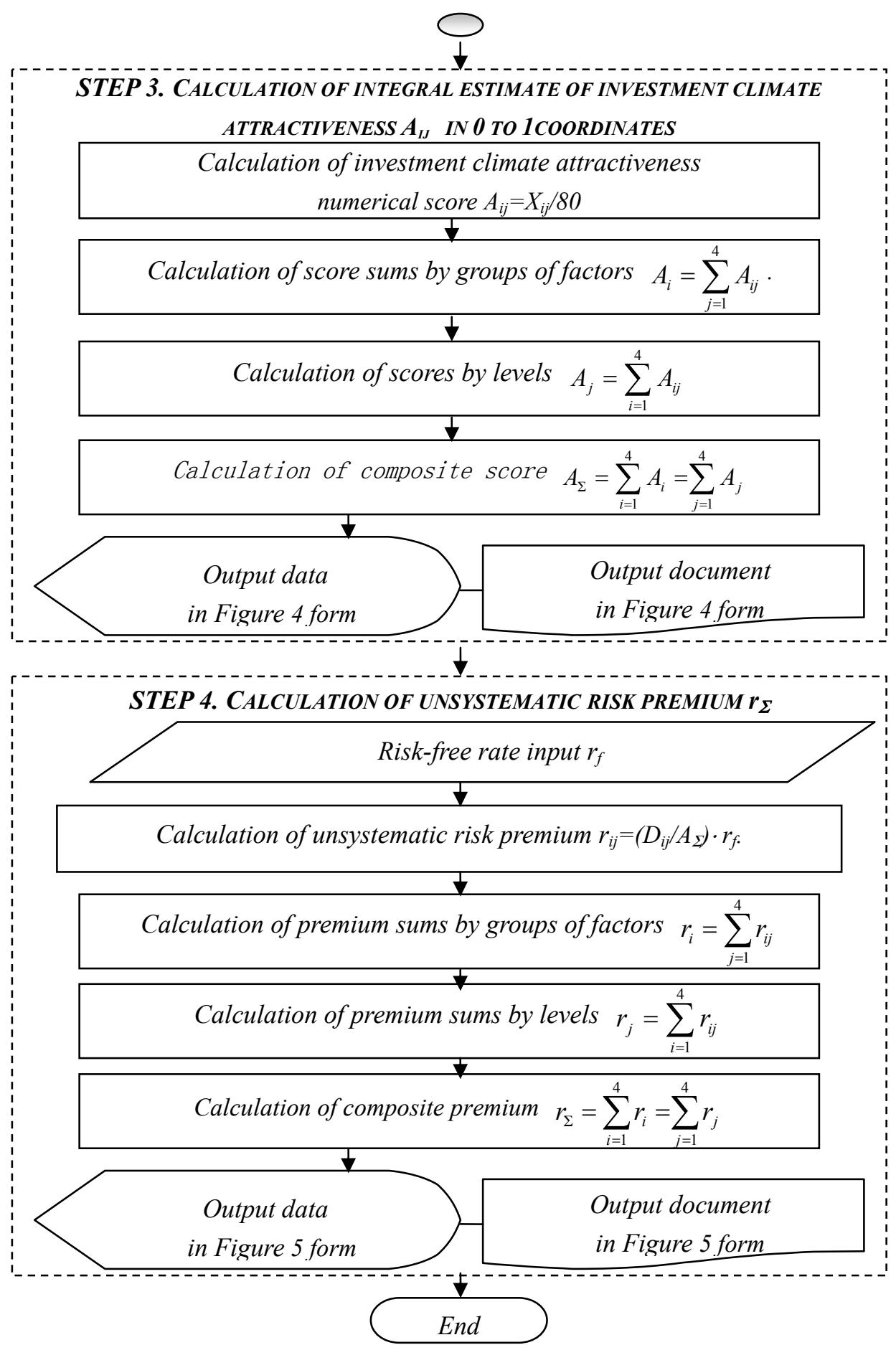

\section{Copyrights}

Copyright for this article is retained by the author(s), with first publication rights granted to the journal.

This is an open-access article distributed under the terms and conditions of the Creative Commons Attribution license (http://creativecommons.org/licenses/by/4.0/). 